\title{
Mortality in Sickle Cell Disease - A Population Based Study in an Aboriginal Community in the Gudalur Valley, Tamil Nadu, India
}

\author{
VEENA SHESHADRI ${ }^{1}$, Shabeer PK ${ }^{1}$, Vatshalan Santhirapalan ${ }^{2}$, Anusha Jayaraman ${ }^{2}$, \\ Lakshmanan Krishnamurti $^{3}$, and Nandakumar Menon ${ }^{1}$ \\ ${ }^{1}$ ASHWINI Gudalur Adivasi Hospital \\ ${ }^{2}$ Harvard Medical School/Boston Children's Hospital \\ ${ }^{3}$ Emory University School of Medicine
}

October 22, 2020

\begin{abstract}
Background: Sickle cell disease (SCD), the commonest monogenic disorder, affects more than 300,000 births annually, with 44,000 in India. While the clinical phenotype of SCD is considered to be milder in aboriginal populations in India, there is a paucity of data on outcomes. To determine the severity of SCD in this population, we studied mortality rates and causes of mortality in a longitudinal cohort of patients with SCD in a remote aboriginal community in India receiving communitybased comprehensive care. Procedures: Causes of death in this cohort from January 2008 to December 2018 were analyzed. Details were collected from hospital records and in case of deaths at home, by utilizing the WHO verbal autopsy questionnaire. Results: The cohort consisted of 157 patients belonging to the Paniya, Betta Kurumba, Kattunyakan, and Mullu Kurumba tribes. During the study period, there were 22 deaths, all from the Paniya tribe. Twelve deaths (54.5\%) occurred in the hospital and the remaining at home $(45.5 \%)$ reflecting a crude mortality rate of 140 per 1000 population. $25 \%$ of deaths occurred in the 6-18 age group. There were no deaths in the 0-5 age group. The median age of death was 25 years, which was 20 years less than in the non-SCD aboriginal population. The leading causes of death were acute chest syndrome, anemia, and sepsis among the SCD patients and stroke and suicides in the non-SCD aboriginal population Conclusion: SCD is a severe disease among the Gudalur Valley's aboriginal population with a significant risk of premature mortality.
\end{abstract}

\section{Introduction}

Sickle cell disease (SCD), an autosomal recessive disorder of the red blood cell, is the commonest monogenic disease with more than 300,000 affected births annually worldwide, mostly in low and middle-income countries. $^{1,2}$ The deformed red cells in SCD lead to recurrent acute vaso - occlusive episodes, hemolysis, anemia, organ damage resulting in impaired quality of life, and premature mortality. ${ }^{3}$ SCD was first described in India in 1952 among the Toda and Irula tribes living in the mountainous regions to the southeast of the Gudalur Valley in the Nilgiri Hills of Tamil Nadu, in southern India. ${ }^{4}$ The $\beta^{\mathrm{s}}$ gene is now known to be widespread among the aboriginal population of the Deccan plateau of Central India, Orissa, Wayanad district of Kerala with a frequency between $5 \%$ to $31 \% .^{5}$ Piels et al estimated that, in 2010, three countries, India, Nigeria, and the Democratic Republic of the Congo accounted for more than half the births with this disease globally. ${ }^{1}$ In India, the aboriginal or scheduled tribes (ST) populations form $8.6 \%$ of the total population constituting 104 million individuals. ${ }^{6}$ It is estimated that in 2010 approximately 44,400 babies with SCD were born in India, ${ }^{1}$ which is more than 20 times the number born in the US. ${ }^{7}$

While SCD is associated with loss of approximately 22 years of life expectancy, this is likely to be impacted by genetic, environmental, socioeconomic factors. ${ }^{8}$ A previous study from the State of Orissa, ${ }^{9}$ had suggested that the clinical phenotype of SCD observed in the aboriginal population may be milder. A study from 
the neighboring District of Wayanad in Kerala stated that they survive longer than individuals of African or Caribbean descent. However, this latter observation may be erroneous, being based on a relatively small cross-sectional study. ${ }^{10}$ As there is limited literature on the mortality rate of SCD in the aboriginal population, we undertook a retrospective cohort study to determine the rates and causes of mortality due to SCD in this community.

\section{Materials and Methods}

We describe an 11-year retrospective cohort study performed at the Gudalur Adivasi Hospital. We analyzed the data of all patients with a diagnosis of SCD, who were followed up at the Hospital and community Area Centers from January 2008 to December 2018.

The Association for Health and Welfare in the Nilgiris (ASHWINI), a charitable non -governmental organization, was established in 1990 in the Gudalur Valley, a remote part of the Nilgiri hills of Tamilnadu in Southern India, to work with the marginalized and displaced aboriginals living there. ASHWINI's Board consists of aboriginal members with a physician serving in an advisory capacity. ASHWINI trained aboriginals as nurses, pharmacists, laboratory technicians, community health workers, paramedics, accountants, etc. and set up a Comprehensive Health System comprising of 200 village-based health workers, eight primary care Area Centers each manned by two trained aboriginal nurses, and a 50 bed well equipped secondary hospital, the Gudalur Adivasi Hospital (GAH) ${ }^{11}$

This population of 18,506 individuals is made up of four distinct aboriginal groups: Paniya (58\%), Betta Kurumba (22\%), Kattunayakan (13\%), and Mullu Kurumba (7\%), classified by the Government of India as Particularly Vulnerable Groups (formerly Primitive Tribal Groups).

The SCD program was started in 1997 with the establishment of the hemoglobin electrophoresis diagnostic facility. In 2004, with the support of the Government of Tamil Nadu, the program was greatly enhanced. Screening for SCD was started in this population in the villages, Area Centers, and GAH as a standard of care, using the sodium metabisulfite sickle cell preparation test. Positive samples underwent cellulose acetate electrophoresis to be differentiated into HbAS, Sickle Cell Trait (SCT) and HbSS, SCD

In Dec 2011, neonatal screening for SCD by High Performance Liquid Chromatography (HPLC) performed by an accredited laboratory (Neogens Lab, Bangalore) was initiated at GAH.

In this cohort of patients diagnosed with SCD, a standardized bundle of SCD care, termed "comprehensive care" was delivered, inclusive of counseling, healthcare review either at the Area Centers or GAH, multivitamins, iron, and analgesics. From 2005, prophylactic penicillin until 5 years of age was offered; symptomatic patients and those with a history of admissions in crisis were started on 5 hydroxyurea (5HU) at $10 \mathrm{mg} / \mathrm{kg}$ body weight with monthly and later, when this dosage was found to be safe, three monthly monitoring of the white blood cell count. In 2011 the polysaccharide pneumococcal vaccine was introduced, as this was not part of the National Immunization Program, and administered at the age of 2 years and penicillin discontinued.

We reviewed hospital medical records of SCD patients who died in the hospital and extracted the details of demography and mortality including sex, age, genotype, date of death, and their causes. The data of the patients with missing hospital records and deaths outside the hospital were collected utilizing World Health Organization verbal autopsy (WHO VA 2016) ${ }^{12}$ questionnaire from close associates of the deceased and a semi-structured questionnaire added to get a clear understanding of the causes which lead to death, using the Anderson Newman behavioral model of health service use, social-ecological and social autopsy models. ${ }^{13,14}$ No post mortem autopsies were performed.

We investigated the age of death in the general aboriginal population during the study period. Of note, the accurate age of older adults in the aboriginal population was difficult to determine because of the absence of formal registration of births before 1990 in this remote region, even though the compulsory registration of births and deaths was introduced by the Government of India in $1969 .{ }^{15}$ Thus the lack of birth certificates and varied self-reporting of age by illiterate aboriginals could lead to uncertainty about the accurate age of 
the older individuals. The age of death in this group was determined using the village census list. However, the age of the younger people was accurate as it was taken from their birth records with the Unique Id numbers.

The study was approved by the ASHWINI institutional review board

\section{Statistics}

Descriptive statistical measures were calculated and overall crude mortality rate and yearly mortality rates were calculated.

\section{Results}

Between Sept. 1997 and Dec. 2018, 13,144 individuals were screened for sickle cell disease in the community and the hospital. Of those screened, 1102 (8.4\%) were found to have SCT, and 149 (1.1\%) to have SCD. Of the 149 SCD patients, eight had died before Jan 2008, leaving a cohort of 141 aboriginals with SCD at the end of Dec. 2018.

As of Dec 2018, out of a total of 1,400 newborns screened, 239 (17.1\%) were found to have SCT and 16 (1.1 $\%)$ to have SCD. Thus, the total cohort studied in this retrospective analysis from Jan 2008 to Dec 2018 was 157, the diagnosis of SCD was confirmed by either hemoglobin electrophoresis or HPLC. (Table1)

Fifty-one percent of the cohort was female. The majority of the patients with SCD were from the Paniya tribe $63.7 \%$, with $17.8 \%$ from the Mullu Kurumba tribe, $10.8 \%$ from the Betta Kurumba tribe, and $8.3 \%$ from the Kattunayakan tribe.

The overall crude mortality rate was $14 \%$ (22/157) or 140 per 1000 population. All 22 deaths were from the Paniya tribe with a mortality rate of $22.2 \%$ (22/99) or 222 per 1000 Paniya population. (Table 2).

In the cohort of SCD patients who died, the median age of death was 24.5 years; in females 20.5 years and males 27 years.

Seventy percent of the deaths were in the 6-29 age group, $45 \%$ of deaths being in the 19-29 age group, followed by $25 \%$ in the 6-18 age group. There were no deaths in the 0-5 age group. Despite the comprehensive care package, none of the SCD children $<5$ years age took prophylactic penicillin, as the mothers were reluctant to administer the antibiotic to their apparently healthy babies. Even with the availability of the polysaccharide pneumococcal vaccine free of cost outside the National Immunization Program, they had not received it. Their intake of iron and multivitamins was also inconsistent.

More deaths 59.1\% (13/22) occurred among the males with SCD. Hospital deaths accounted for 54.5\% $(12 / 22)$ of deaths and the remaining deaths occurred at home (45.5\%). A total of 12 deaths were reviewed by verbal autopsy. All causes of death were attributed to the sequelae of SCD. There were no deaths attributable to accidents or suicides. The causes of death were acute chest syndrome $31.8 \%$, severe anemia $22.7 \%$, sepsis $18.2 \%$, pregnancy-related $9.1 \%$, acute abdomen $9.1 \%$, dehydration $4.6 \%$, and stroke $4.6 \%$ (Table 3 ).

The annual mortality rate per 100 sickle cell disease population was 4.3 in 2008 and 0.7 at the end of the study period in 2018. Between 2008 and 2018, the mortality rate was variable, but the overall rate has been trending down (Figure 1).

During the study period, 1771 individuals from the non-SCD aboriginal population died; the mortality rate was $9.6 \%$ and the median age of death was 55 years. The ten commonest causes of deaths were stroke (12.8\%), suicides $(10.8 \%)$, cardiovascular diseases $(10.5 \%)$, cancer $(10.1 \%)$, old age-related $(9.8 \%),<5$ years $(8.2 \%)$, unknown (6.8\%), trauma (accidents/homicide/alcohol-related violence) (6.1\%), COPD/asthma (3.7\%) and acute gastroenteritis (3\%).

\section{Discussion}

As demonstrated in this study, SCD is a serious disease in the aboriginal population of the Gudalur Valley, as there is a substantially higher risk of premature death. 'Despite the high prevalence of SCD among the 
aboriginal population, there have been only a few studies documenting the causes of death and mortality rates. ${ }^{16}$ The mortality rate identified in this study is comparable to that observed in Brazilian patients (16.8 \%) with SCD. ${ }^{17}$

Based on our newborn screening data we found an SCT rate of $17.1 \%$ and a SCD rate of $1.1 \%$ respectively. The SCT rate of $8.4 \%$ by Hb electrophoresis could be falsely low because of duplications as some individuals would have been tested more than once as their Unique ID numbers were recorded inaccurately. Of the 16 newborns detected to have SCD screened over 7 years (Dec 2011 - 2018), there were no deaths in the $<5$ age group. This low mortality is intriguing as it contrasts with other studies in low resource settings ${ }^{18,19}$ and especially since none of the patients received prophylactic penicillin or pneumococcal vaccine. However, three of the $16<5$ children were admitted at GAH with respiratory infections and one with acute splenic sequestration requiring blood transfusion. Survival of all the $<5$ children in this aboriginal SCD population may thus, potentially, be related to timely medical care.

Seventy percent (70\%) of deaths were in the 6-29 age group, with the 19-29 y age group having the highest mortality $(45.4 \%)$ with $24.6 \%$ of deaths in the $6-18$ age group. In the study from Brazil, out of 281 SCD deaths, most occurred in the 6-11 year age group $(35.9 \%)^{16}$.

The median age of death in the non-SCD aboriginals population of Gudalur during the study period was 55 years, which is 20 years more than the median age of death of 25 years in those with SCD. These data suggest significant premature mortality in this SCD aboriginal population. The high rate of early mortality reported in this study stands in contrast to the report by Feroze et al from the adjacent district of Wayanad which suggested that SCD disease is of a milder phenotype in the aboriginal population. ${ }^{10}$ As the authors state, their study of 23 patients with SCD was too small to draw any conclusions about disease phenotype. Further, they provided no details of the setting in which the individuals received medical care or the completeness of the collection of clinical complications. It is of interest that the authors report the differences in literacy and outcomes between different tribes in the area. They too observed that the Paniyas had the lowest literacy and the highest mortality. Thus, the study of disease phenotype in aboriginal populations who are faced with extreme isolation and severe disadvantage must be carried out in the context of comprehensive care, close follow up and surveillance, and accounting for social determinants of health.

The predominance of deaths in males is inconsistent with the overall cohort characteristics (Table 1) but is consistent with the greater survival in women as reported in other studies ${ }^{17,20}$

Just under half the deaths occurred at home despite the availability of free government ambulance services and free medical care at GAH. The persistence of barriers to care in a community owned, community centered system of care in this extremely disadvantaged community bears further investigation.

The causes of death in our SCD population were the sequelae of the disease itself. None of these patients died of non-communicable diseases, suicides, or trauma, which were the common causes of death in the non-SCD aboriginal community. In our cohort, the overwhelming majority of the deaths occurred due to acute chest syndrome, anemia, and sepsis which have been described as leading causes of death in other studies. ${ }^{21,22}$ The absence of deaths due to trauma can be explained by the fact that, unlike the non-SCD aboriginal population, they do not undertake hazardous work.

The Paniya tribe formed the greater part of the diagnosed SCD cases (64\%), which is consistent with their being the largest group, constituting $58 \%$ of the aboriginal population in the Gudalur Valley. It is not surprising that all the deaths occurred in the Paniya tribe. They constitute the most disadvantaged of the four aboriginal groups and were, until recently, bonded laborers, a modern form of slavery. Despite their liberation from bonded labor, the Paniyas continue to experience several 'vulnerability traps' of isolation, education deficits, ${ }^{10}$ indebtedness, alcohol use, loss of community bonds, and traditional leadership. These factors may explain why health outcomes in the Paniya population continue to be poorer than the other aboriginal populations in the area. These findings may suggest that improving health outcomes in this vulnerable population, would require a broad strategy that addresses the social determinants of health and their intersections with healthcare delivery and outcomes. It is noteworthy that although the Mullu 
Kurumbas form only $7 \%$ of the population, $17.8 \%$ of the SCD patients were from this group. This is probably because of the practice of endogamy within this small tribal community

Observed mortality has decreased between 2008 to 2018. Early screening for SCD and the availability of a comprehensive health system with community-based programs may account for some of this improvement. It may also be secondary to higher economic and social status resulting from increased accessibility and availability of education and employment.

A major limitation of the study is that many of the deaths occurred outside the hospital setting. However, since the study was conducted in the context of a community directed and community based comprehensive care, we are confident that we have been able to track all births and deaths in this community. All aboriginal deaths in this area are reported to the Area Nurses and AMS (Aboriginal Advancement Society) members, who support and are also often present for the last rites. Deaths of individuals working outside the area are uncommon but are also reported. The Area Nurses are all from the aboriginal community and have extensive personal connections. Of note, the accurate age of the older adults in the aboriginal population is difficult to determine because of the absence of birth certificates and varied self-reporting of age. The age of death in this group was determined using the village census list. However, the age of the younger people was accurate as it was taken from their birth records which are more organized since 1990 when ASHWINI started and a Unique ID number was given to each individual.

We have presented the results over 11 years and hence could not account for multiple population-level changes that may have occurred during the study period. As there were improvements in the educational and financial conditions within the aboriginal population during this period, the decrease in mortality rate observed cannot be attributed to the availability of comprehensive and integrated sickle cell care alone. Furthermore, the events preceding home deaths were analyzed and documented using WHO VA tool ${ }^{12}$. The causes of mortality recorded in this survey may not be entirely reliable considering the time that may have elapsed since death, introducing recall bias. Also, there could have been more than one reason for death, but we only recorded the primary cause of death.

In conclusion, the data presented in this manuscript indicate that SCD is a disease with high premature mortality among the aboriginal population of the Gudalur Valley. The recognition of the severity of SCD in this population provides the rationale for the design and implementation of newborn screening and comprehensive care for SCD. These programs must also address the socioeconomic and cultural barriers to the delivery of care to these extremely disadvantaged aboriginal populations.

Conflicts of Interest: None declared

Acknowledgments: We acknowledge Ms.Malathi Manikandan and Ms. Pradeepa for the data collection. We thank Drs. Anna Oommen, Roshina Sunny, and Meredith Brooks for their valuable advice. We thank the Government of Tamil Nadu for their support.

\section{References :}

1. Piel FB, Hay SI, Gupta S, Weatherall DJ, Williams TN. Global burden of sickle cell anemia in children <5, 2010-2050: modelling based on demographics, excess mortality, and interventions. PLoS Med. 2013;10: e1001484.

2. McGann PT. Sickle Cell Anemia: An Underappreciated and Unaddressed Contributor to Global Childhood Mortality. The Journal of Pediatrics 2014 July;165(1), 18-22

3. Ware RE, de Montalembert M, Tshilolo L, Abboud MR. Sickle cell disease. Lancet 2017;390(10091):311-323.

4. Lehman H, Cutbush M. Sickle cell trait in southern India. Brit Med J 1952; 1: 404-5.

5. Kaur M, Das GP, Verma IC. Sickle cell trait \& disease among aboriginal communities in Orissa, Madhya Pradesh \& Kerala: Indian J Med Res 1997 Mar;105:111-6

6. Census of India 2011. Office of the Registrar General and Census Commissioner.

Ministry of Home Affairs, Govt of India.http://www.censusindia.gov.in 
1. Therrell BL, Lloyd- Puryear MA., Eckman JR., Mann MY Newborn Screening for sickle cell disease in the United States: A review of data spanning 2 decades Semin Perinatol 2015 Apr;39(3):238-51

2. Lubeck D, Agodoa I, Bhakta N et al. Estimated life expectancy and income of patients with sickle cell disease compared with those without sickle cell disease. JAMA Network Open. 2019;2(11):e1915374.

3. Kar BC, Satapathy RK, Kulozik AE, Kulozik M, Sirr S, Serjeant BE, et al. Sickle cell disease in Orissa State, India. Lancet. 1986;ii:1198-201.

4. Feroze M, Aravindan K. Sickle cell disease in Wayanad, Kerala: Gene frequencies and disease characteristics. National Medical Journal of India 2001; 14:267-270

5. Nimgaonkar V, Krishnamurti L, Prabhakar H, Menon N. Comprehensive integrated care for patients with sickle cell disease in a remote aboriginal population in southern India. Pediatr Blood Cancer 2014; 61: 702-705.

6. World Health Organization. Verbal autopsy standards: 2016 WHO verbal autopsy instrument. Geneva, Switzerland: World Health Organization 2016. Available from: http://www.who.int/healthinfo/statistics/verbalautopsystandards/en/

7. Anderson and Newman. Revisiting the behavioral model and access to medical care: does it matter? Journal of Health and Social Behavior. 1995; 36:1-10. Framework of Health Services Utilization.

8. Kumar S, Crouse Quinn S, Kim KH, Musa D, Hilyard, KM, \& Freimuth VS. (n.d.). The Social Ecological Model as a Framework for Determinants of 2009 H1N1 Influenza Vaccine Uptake in the US.https://doi.org/10.1177/1090198111415105

9. Registration of Births and Deaths Act 1969 Accessed at www.censusindia.gov.in.

10. Shah P, Bhagat VM, Patel K, Patel C. Pattern of mortality in sickle cell disease: an autopsy study. Int J Res Med Sci. 2017;5:2115-2119

11. Lobo CLC, Nascimento EMD, Jesus LJC, Freitas TG, Lugon JR, Ballas SK. Mortality in children, adolescents, and adults with sickle cell anemia in Rio de Janeiro, Brazil. Hematol Transfus Cell Ther. 2018;40(1):37-42

12. Thomas AN, Pattison C, Sergeant GR. Causes of death in sickle-cell disease in Jamaica. BMJ 1982:285(633-635)

13. Grosse SD, Odame I, Atrash HK, Amendah DD, Piel FB, Williams TN. Sickle cell disease in Africa: a neglected cause of early childhood mortality Am J Prev Med 2011 Dec;41(6 Suppl 4): S398-405

14. Wierenga KJ, Hambleton IR, Lewis NA. Survival estimates for patients with homozygous sickle-cell disease in Jamaica: a clinic-based population study. Lancet 2001;357(9257):80-3.

15. Al-Suliman A, Elsarraf N.A, Baqishi M, Homrany H, Bousbiah J, Farouk E. Patterns of mortality in adult sickle cell disease in Al-Hasa region of Saudi Arabia. Ann Saudi Med 2006; 26:487-488.

16. Serjeant GR, Chin N, Asnani MR, Serjeant BE, Mason P, Hambleton I.R, Knight-Madden JM. Causes of death and early life determinants of survival in homozygous sickle cell disease: The Jamaican cohort study from birth. PLoS One.2018;13:e019271.

\section{FIGURE 1. Annual Mortality Rate of SCD Patients With Trend}

\section{Hosted file}

TABLE I.pdf available at https://authorea.com/users/369409/articles/488271-mortality-insickle-cell-disease-a-population-based-study-in-an-aboriginal-community-in-the-gudalurvalley-tamil-nadu-india

\section{Hosted file}

TABLE II.pdf available at https://authorea.com/users/369409/articles/488271-mortality-insickle-cell-disease-a-population-based-study-in-an-aboriginal-community-in-the-gudalurvalley-tamil-nadu-india

\section{Hosted file}

TABLE III.pdf available at https://authorea.com/users/369409/articles/488271-mortality-insickle-cell-disease-a-population-based-study-in-an-aboriginal-community-in-the-gudalur- 
valley-tamil-nadu-india

FIGURE 1. Annual Mortality Rate of SCD Patients With Trend

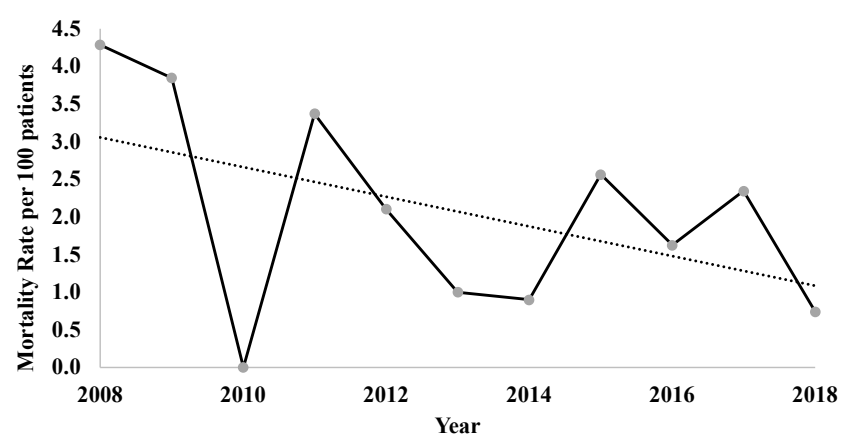

